\title{
Finishing OF THE SURFACE OF HOLES BY FLEX-HONE TOOL
}

\author{
Michal Skrzyniarz, Stanislaw Adamczak, Lukasz Nowakowski, \\ Tomasz Kozior \& Edward Miko
}
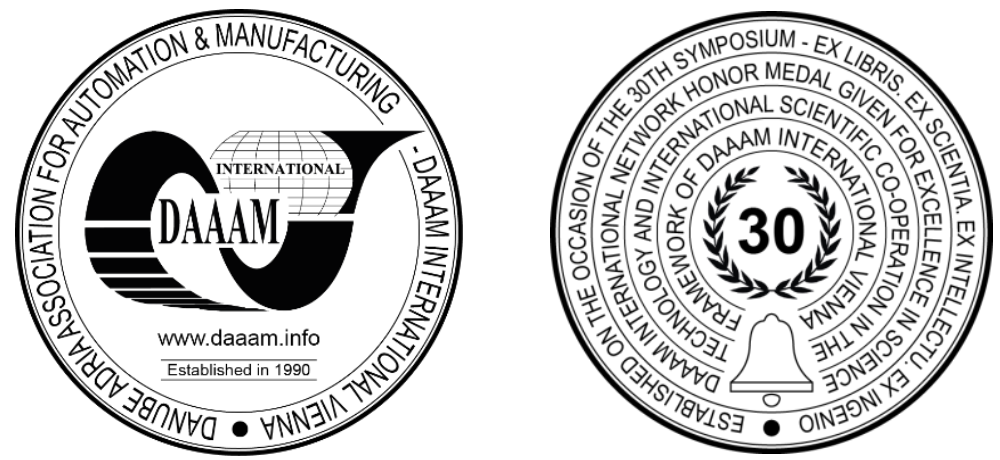

This Publication has to be referred as: Skrzyniarz, M[ichal]; Adamczak, S[tanislaw]; Nowakowski, L[ukasz]; Kozior, T[omasz] \& Miko, E[dward] (2019). Finishing of the Surface of Holes by Flex-Hone Tool, Proceedings of the 30th DAAAM International Symposium, pp.0860-0863, B. Katalinic (Ed.), Published by DAAAM International, ISBN 9783-902734-22-8, ISSN 1726-9679, Vienna, Austria

DOI: $10.2507 / 30$ th.daaam.proceedings.119

\begin{abstract}
The requirements of designers in the manufacturing of precision machine parts refer to the dimensional and shape accuracy and geometric structure of the surface. These requirements must be met in order to ensure proper operation of the cooperating parts. The main goal of the article is to check the dimensional and shape accuracy and selected parameters of the geometrical structure of the holes surface made with a boring bar and a flex-hone tool. The shape and dimensional accuracy tests were carried out on the Talyrond 365 measuring system. Measurements of the geometric structure of the surface were made on the Talysurf CCI optical profilometer. The entire machining process was carried out on a vertical milling centre DMG DMU 50.
\end{abstract}

Keywords: honing; finishing of holes; dimensional and shape accuracy; flex-hone tool.

\section{Introduction}

Making precise machine parts for industry car or air is a time-consuming and expensive process. Requirements for co-operating part of the machine for quality shape accuracy and geometric structure of the surfaces make the manufacturing process consists of several complex processes. The high requirements regarding to shape and dimensional accuracy and the geometrical structure of the hole surfaces established by the constructors must be implemented to ensure proper operation and service life of manufactured parts such as bushings of internal combustion engines, cylinders of servo motors, etc. To meet the high demands beyond conventional operations in machining, i.e. turning, milling, drilling, boring and grinding, many processes were created dedicated to the finishing of machine parts [1]. One of such operations is the honing process. Honing is the last treatment that shapes the shape and quality of the surface [2]. It is usually performed after such operations as: grinding, boring or plastic working. The purpose of the honing process is to improve the dimensional and shape accuracy of the parts produced [3], [4] and to give it the appropriate structure [5], [6], [7]. This process is carried out using special tools in the form of whetstones or flex-hone, which during the work make a rotary motion combined with the reciprocating working movement of the tool. In the case of tools in the form of whetstone, the additional pressure is controlled by the pressure of the tool on the work surface, which is not controlled by the flex-hone tools [8]. Due to the low intensity of the process and the use of machining fluids, this process does not have the thermal effect on the workpiece [9], [10]. 
The main purpose of the article is to check the shape and dimensional accuracy and geometric parameters of the surface of the holes made by flex-hone tool to determine the suitability of using this tool. For this purpose, it was checked how the honing process affects the dimensional accuracy of the holes. Does the honing process introduce shape errors and how the selected SGP surface parameters change. The obtained test results are discussed in the rest of the work.

\section{Research methods}

The tests were carried out on a vertical DMG DMU 50 milling centre. The machined material was a brass cylinder MO58 with a diameter of $\varnothing 26 \mathrm{~mm}$ and a height of $21 \mathrm{~mm}$. The machining process was carried out in several operations. The first operation was the drilling process. It was carried out using a Sandvik Coromant CoroDrill 880 drill with a diameter of $\varnothing 25 \mathrm{~mm}$ (step 1) with a cutting speed $\mathrm{v}_{\mathrm{c}}=155 \mathrm{~m} / \mathrm{min}$ and feed rate $\mathrm{f}_{\mathrm{n}}=0.1 \mathrm{~mm} / \mathrm{rev}$. Then, the hole was milled to $27.8 \mathrm{~mm}$ using a mill R216.32-12025-AK38A H10F $12 \mathrm{~mm}$ diameter (step 2) with a cutting speed $\mathrm{v}_{\mathrm{c}}=180 \mathrm{~m} / \mathrm{min}$ and feed rate $\mathrm{f}_{\mathrm{z}}=0.02 \mathrm{~mm} /$ blade. The finishing operation in the form of boring was carried out with a boring bar equipped with a TCM T06 T1 02-PF 5015 cutting insert (step 3). The cutting speed during boring was set at the level of $\mathrm{v}_{\mathrm{c}}=460 \mathrm{~m} / \mathrm{min}$ and the feed was $\mathrm{f}_{\mathrm{n}}=0.06 \mathrm{~mm} / \mathrm{rev}$. The last treatment (step 4) was the honing process with a flex-hone tool with variable process control parameters.

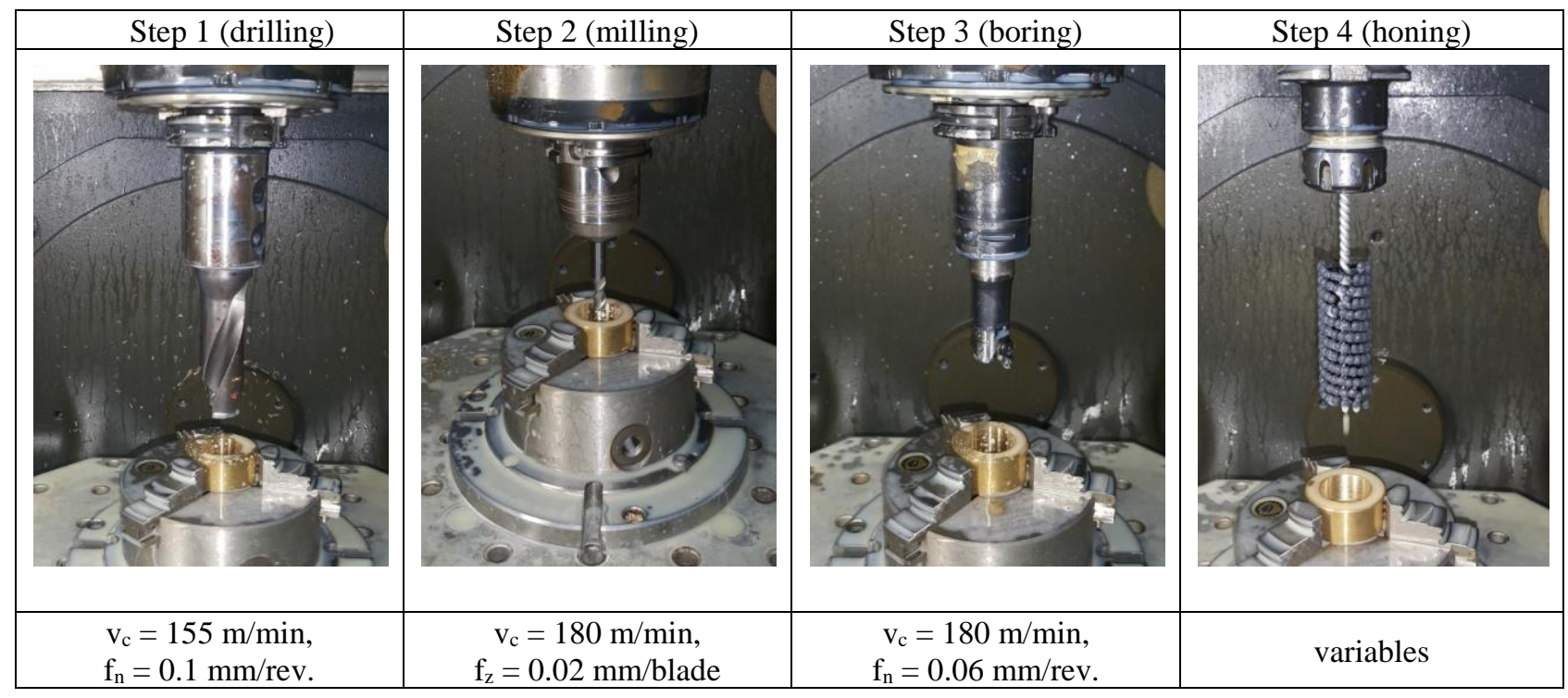

Table 1. Operations of making holes

The honing process was carried out with the speed $\mathrm{n}=500 \mathrm{rpm}\left(\mathrm{v}_{\mathrm{c}}=44 \mathrm{~m} / \mathrm{min}\right)$, while the reciprocating movement was carried out in the range $+-20 \mathrm{~mm}$ with the feed rate in the range from 2400 to $7200 \mathrm{~mm} /$ min increased for each sample by $1200 \mathrm{~mm} / \mathrm{min}$. The process of honing consisted of 30 working movements with adding a cooling and lubricating liquid. Experimental research was carried out on six samples, as a result of which six cylindrical surfaces were produced. The first surface is the reference surface that has been obtained as a result of the boring process (sample 1). Subsequent surfaces from 2 to 6 , after the boring process were honed with variable speed of reciprocating movement (sample No. $2=2400 \mathrm{~mm} / \mathrm{min}$, sample No. $3=3600 \mathrm{~mm} / \mathrm{min}$, sample No. $4=4800 \mathrm{~mm} / \mathrm{min}$, sample No. $5=6000$ $\mathrm{mm} / \mathrm{min}$, sample No. $6=7200 \mathrm{~mm} / \mathrm{min}$ ). After the machining process, measurements of the dimensional and shape accuracy of the machined cylindrical surfaces were carried out using the Talyrond 365 contour measuring system and the geometric structure of the surface, using the Talysurf CCI Lite optical profilometer.

\section{Test results}

A summary of the results of measurements the dimensional and shape accuracy are presented in tables 2 and 3 . Table 2 contains the measurements of the cylinder errors of the surface using a Gauss filter with the analysis of components from 1 to 15 of the wave. In this case, the shape error of the produced surfaces was analyzed. The analysis of the results presented in Table 2 shows that the smallest value of cylindrical deviation CYLt $=19.2 \mu \mathrm{m}$ was obtained in the boring process (sample No. 1). The main reason for the increase in cylindrical deviation after the honing process is the flex-hone construction, which is flexible. At the entrance to the workpiece, a flex-hone tool caused the increasing of the hole, which resulted in the introduction of an additional deviation of the shape in the longitudinal section having the character of a cone. 


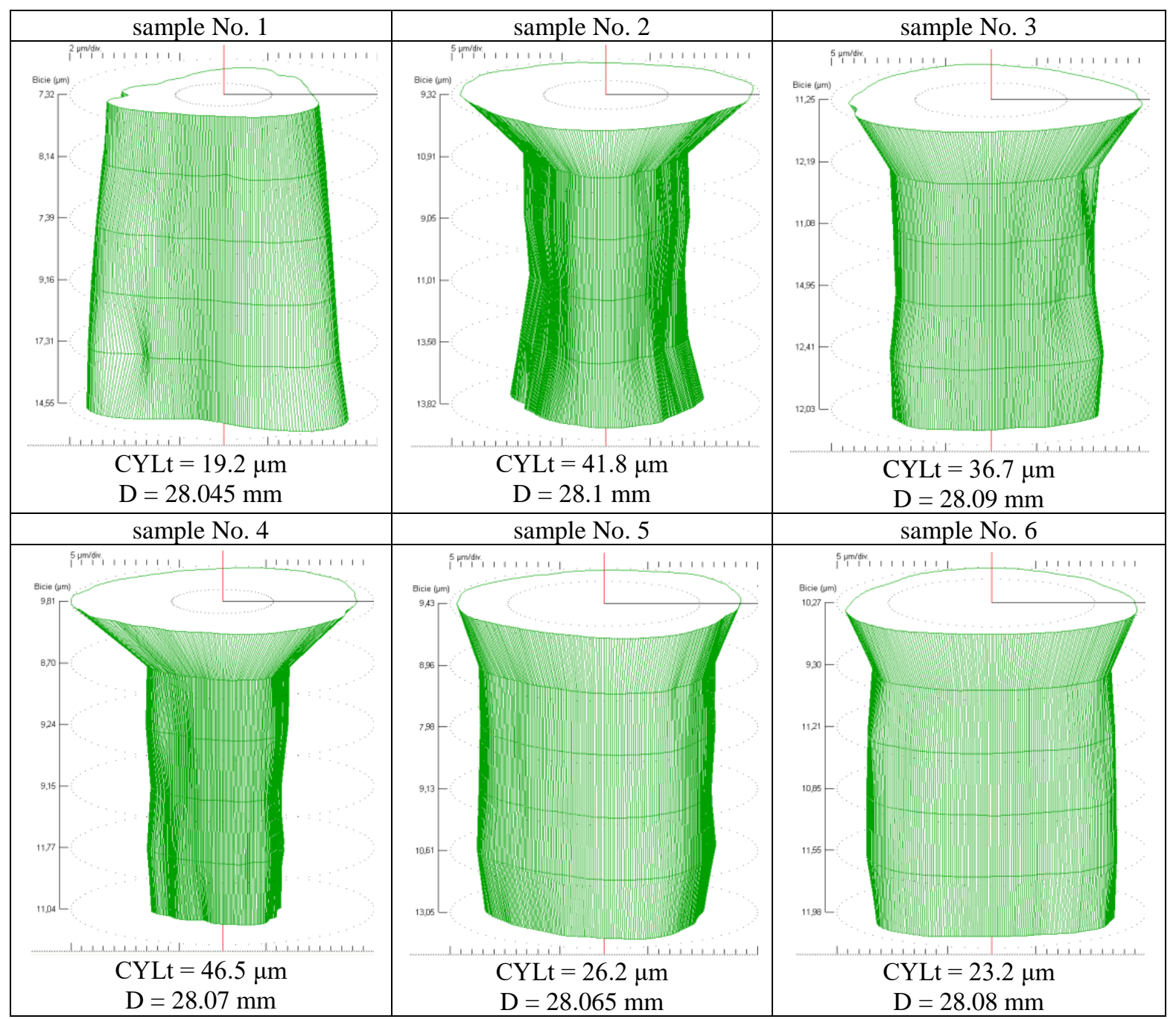

Table 2. Measurement of the shape and dimensional accuracy

The gradual increase in the feed speed of the reciprocating movement for each sample by $1200 \mathrm{~mm} / \mathrm{min}$ in combination with the flexible properties of the flex-hone toll has a significant impact on the dimensional accuracy of the smoothed hole. Before starting the honing process, holes with a diameter of $28.045 \mathrm{~mm}$ were made in each sample. As a result of the finishing process of the holes by honing with a flex-hole tool, the diameters carried out showed that the largest dimensional changes of the measured diameters were obtained for sample No. $2(\mathrm{D}=28.1 \mathrm{~mm})$, while the smallest change in diameter was obtained for sample No. $5(\mathrm{D}=28.065 \mathrm{~mm})$. The main factor that influence on the change the diameter of the honed holes was the extension of the time of impact of the abrasive elements of the flex-hone tool on the surface, which resulted from the selected feed speeds. For sample No. 2, the machining lasted the longest.

\begin{tabular}{|c|c|c|c|c|c|c|}
\hline Sample & Ra, $\mu \mathrm{m}$ & RSm, mm & Rt, $\mu \mathrm{m}$ & $\mathrm{Rv}, \mu \mathrm{m}$ & $\mathrm{Sa}, \mu \mathrm{m}$ & $\mathrm{Sz}, \mu \mathrm{m}$ \\
\hline No. 1 & 0.9 & 0.04 & 5.3 & 2.2 & 0.9 & 8.7 \\
\hline No. 2 & 1.1 & 0.04 & 8.3 & 4.9 & 1.5 & 18.4 \\
\hline No. 3 & 1.4 & 0.04 & 10.4 & 5.8 & 1.6 & 18.7 \\
\hline No. 4 & 1.6 & 0.05 & 11.8 & 7.6 & 1.5 & 27.1 \\
\hline No. 5 & 1.2 & 0.03 & 7.9 & 7.9 & 1.2 & 16.7 \\
\hline No. 6 & 1.7 & 0.05 & 9.5 & 4.8 & 1.5 & 11.7 \\
\hline
\end{tabular}

Table 3. Selected 2D and 3D parameters of the surface roughness

In Table 3 selected 2D and 3D parameters of the surface roughness are presented. From the analysis of selected surface roughness parameters, it was noticed that the honing process with a flex-hone tool increases the values of the analyzed parameters of surface roughness such as: Ra, Rt, Sa and Sz. This is due to the intensive interaction of the grains of the flex-hone tool on the surface. Before starting the honing process, the average measured value of the $\mathrm{Sa}$ and $\mathrm{Ra}$ parameter of the surface roughness of the boring holes was $0.9 \mu \mathrm{m}$. As a result of the honing process, the maximum value of $\mathrm{Sa}=1.6 \mu \mathrm{m}$ was measured for sample No. 3. The smallest value of the parameter $\mathrm{Sa}=1.2 \mu \mathrm{m}$ was obtained for the 
sample No. 5. Analyzing the material share curves, we note that the speed of reciprocating motion is of great importance. The best structure of the so-called plateau based on the Abbott-Firestone curve was obtained for sample No. 4, while the worst for sample No. 6.

\section{Conclusions}

The main purpose of the research was to determine the possibility of using the flex-hone tool in the production of precise holes. In addition, the paper analyzes the impact of processing parameters on the shape and dimensional accuracy and geometric structure of the surface. For this purpose, an experiment was carried out witch first step of making by drilling and milling operations. The second step was boring and honing.

The results of the research have shown that the increase in the speed of the reciprocating movement has an impact on the decrease in the dimensional and shape accuracy and on the parameters of the geometric structure of the surface by increasing the value of the angle between the occurring scratches. The main disadvantage of using a flex-hone tool is that it causes rounding of the edge of the holes when entering the workpiece. Due to the inability to control the force of the tool pressure on the workpiece, it is difficult to predict the size of the allowance on the surface to be left before honing to achieve the assumed dimensional accuracy. Machining with a flex-hone tool is not able to remove the shape errors introduced in the previous machining. In the further part of the work, it is planned to check the intensity of the tool's impact on the workpiece using different sizes of machining allowances to be able to control the dimensional accuracy of the holes.

\section{Acknowledgments}

The paper has been elaborated within the framework of the research project entitled "Theoretical and experimental problems of integrated 3D measurements of elements' surfaces”, reg. no.: 2015/19/B/ST8/02643, ID: 317012, financed by the National Science Centre, Poland.

\section{References}

[1] Nowakowski, L.; Skrzyniarz, M.; \& Miko, E. (2017). The analysis of relative oscillation during face milling, 23rd International Conference Engineering Mechanics 2017, 730-733.

[2] Adamczak, S.; Zmarzły, P.; Kozior, T \& Gogolewski, D. (2017). Analysis of the dimensional accuracy of casting models manufactured by fused deposition modeling technology, 23rd International Conference Engineering Mechanics 2017, 66-69.

[3] Zetek, M.; Vozar, V.; Baksa, T. \& Zetkova, I. (2017).Influence of the Milling Cutter Diameter on the Cutting Tool Life when Machining Inconel 718, Proceedings of the 28th DAAAM International Symposium, pp.0417-0422, B. Katalinic (Ed.), Published by DAAAM International, ISBN 978-3-902734-11-2, ISSN 1726-9679, Vienna, Austria, DOI: 10.2507/28th.daaam.proceedings.058.

[4] Zmarzly, P.; Adamczak, S.; Kozior, T. \& Gogolewski, D. (2018). Surface Texture Quality of Models Manufactured by Additive Technology Fused Deposition Modeling, Proceedings of the 29th DAAAM International Symposium, pp.0853-0859, B. Katalinic (Ed.), Published by DAAAM International, ISBN 978-3-902734-20-4, ISSN 1726-9679, Vienna, Austria DOI: 10.2507/29th.daaam.proceedings.123.

[5] Cus, F. \& Zuperl, U. (2018). Experimental Exploration of Cutting Forces During Milling of Multi-Layered Metal Materials, Proceedings of the 29th DAAAM International Symposium, pp.0144-0148, B. Katalinic (Ed.), Published by DAAAM International, ISBN 978-3-902734-20-4, ISSN 1726-9679, Vienna, Austria DOI:10.2507/29th.daaam.proceedings.020.

[6] Nosal, J.; Brezikova, K. \& Simkulet, V. (2017). Verification of Combined Cutting tool with a Linear Cutting Edge tool, Proceedings of the 28th DAAAM International Symposium, pp.1227-1233, B. Katalinic (Ed.), Published by DAAAM International, ISBN 978-3-902734-11-2, ISSN 1726-9679, Vienna, Austria, DOI: 10.2507/28th.daaam.proceedings.171.

[7] Krajcarz, D.; Bańkowski, D.; \& Młynarczyk, P. (2017). The effect of traverse speed on kerf width in AWJ cutting of ceramic tiles, Procedia Engineering, Vol. 192, 469-473.

[8] Nowakowski, L.; Skrzyniarz, M.; \& Miko, E. (2017). The assessment of the impact of the installation of cutting plates in the body of the cutter on the size of generated vibrations and the geometrical structure of the surface, 23rd International Conference Engineering Mechanics 2017, 734-737.

[10] Bartoszuk, M.; \& Grzesik, W. (2011). Numerical prediction of the interface temperature using updated finite difference approach, Modelling of Machining Operations Book Series: Advanced Materials, Vol. 223, 231-239.

[11] Nowakowski, L.; Skrzyniarz, M.; Miko, E.; Takosoglu, J.; Blasiak, S.; Laski, P.; ...\& Blasiak, M. (2016). Influence of the cutting parameters on the workpiece temperature during face milling, Proc. Int. Conf. Exp. Fluid Mech. 2016, 523-527. 